Practice and career satisfaction patterns among female urologists

\title{
Exploring the patterns of practice and satisfaction among female urologists in Canada
}

Amanda E. Hird, MD ${ }^{1,2}$; Marie-Pier St-Laurent, MD $^{3}$; Geneviève Nadeau, MD, FRCSC 3 ; Lesley Carr, MD, FRCSC ${ }^{1,4}$; Monica Farcas, Meng, MD, FRCSC ${ }^{1,5,6}$

${ }^{1}$ Division of Urology, University of Toronto, Toronto, ON, Canada; ${ }^{2}$ Institute of Health Policy Management and Evaluation, Toronto, ON, Canada; ${ }^{3}$ Division of Urology, Université Laval, Quebec City, QC, Canada; ${ }^{4}$ Division of Urology, Sunnybrook Health Sciences Centre, Toronto, ON, Canada; ${ }^{5}$ Division of Urology, St. Michael's Hospital, Toronto, ON, Canada; ${ }^{6}$ Institute for Biomedical Engineering, Science and Technology (iBest), Toronto, ON, Canada

Cite as: Can Urol Assoc J 2020 March 23; Epub ahead of print.

http://dx.doi.org/10.5489/cuaj.6184

Published online March 23, 2020

$* * *$

\section{Abstract}

Introduction: Our aim was to explore the satisfaction, personal and professional challenges, and practice barriers among female urologists in Canada.

Methods: A literature review was completed to design our survey. Trends with respect to career and personal satisfaction were identified, including academic advancement, mentorship, professional challenges, workplace discrimination, family satisfaction, and remuneration, among others. These key themes were formatted into 44 questions, translated into French, and distributed electronically as a survey to 80 female urology staff across Canada.

Results: Sixty (75.0\%) women completed the survey. Many had been in practice $<5$ years $(44.1 \%)$ and $72.9 \%$ completed a fellowship. Overall, $96.6 \%$ of women were very or somewhat satisfied with their career. Seeing more time-consuming patients and financial constraints within the healthcare system were the greatest source of dissatisfaction. Two-thirds of respondents reported that they received significant mentorship and $40 \%$ found it difficult to find a mentor during their training. Overall, $65.0 \%$ experienced gender discrimination, most commonly from a colleague or a patient. Women who practiced in the community were more likely to report experiencing discrimination compared to women practicing in an academic setting ( $78.1 \%$ vs. $51.9 \%$; $\mathrm{p}=0.034)$. Mean time for maternity leave was $17.1( \pm 8.3)$ weeks, and $29.6 \%$ reported a pregnancy-related complication triggered by their work. Overall, $66.1 \%$ would choose urology again.

Conclusions: It is important to advocate for the wellness of female urologists. To accomplish this, we need to address the challenges revealed in the survey, including supporting women on maternity leave, improving mentorship, and prioritizing female urology leadership initiatives. We 
have established a formal circle of support within the urology community in Canada to achieve these goals.

\section{Introduction}

Roughly equivalent numbers of males and females graduate medical school in Canada ${ }^{1}$. Among practicing physicians registered with the Royal College of Surgeons, 14\% of women choose to go into surgical specialties in contrast to $33 \%$ of men $^{2}$. In Canada, urology has one of the lowest proportion of females $(11.2 \%)$ compared to all other specialties ${ }^{3}$.

While urology remains a male-dominated field ${ }^{4}$, a recent retrospective review of the Canadian Residency Match statistics from 1998 to 2015 demonstrated an increase in the proportion of female applicants who ranked a surgical program as their first choice ${ }^{5}$. There was also a reported increase in the proportion of females applying to urology as their first-choice $\operatorname{program}^{5}$.

As the numbers and percentages of women completing surgical training increase, it is important to understand the work patterns and career decisions of women in the field. Our aim was to explore the current trends in practice and satisfaction, as well as the personal and professional challenges experienced by female urologists in Canada.

\section{Methods}

A systematic literature review was completed to identify current trends in practice and satisfaction among female surgeons. This list of items was reviewed by the coauthors and finalized into a 44item survey. The survey consisted of both multiple choice and open answer questions (Table 1). Demographic variables were collected as categorical or continuous variables where appropriate. Items pertaining to professional and personal challenges were presented in the form of yes/no questions with space to provide an explanation if desired by the respondent. Questions pertaining to satisfaction were presented on a Likert scale (quite a lot, a little, not very much, none). Greatest sources of dissatisfaction and discrimination in the workplace were presented as a list of options with space for participants to add additional responses that did not appear on the predetermined list. Some questions were left completely open to written responses, specifically "How do you practice differently than your male counterparts". A complete version of the survey is presented in Supplementary Appendix 1.

This list was then translated into French and distributed (by email) to 42 English-speaking and 38 French-speaking female board-certified urologists in Canada (Figure 1). Current fellows were not included in the study. Multiple resources were used to identify actively practicing female urologists in Canada, including the Canadian Urological Association (CUA) database as well as internet searches of University departments, and known contacts of the co-authors. Given the 
personal nature of the responses, all responses were collected online in an anonymous fashion via SurveyMonkey. A response was not required for each survey answer. No respondent identifier was used. We did not ask specifically for the current age of the respondents, given the anticipated small sample size, to maintain anonymity. Similarly, categorical responses were used for specific questions (such as number of years in practice) to maintain confidentiality. Ethics approval was obtained from the St. Michael's Hospital Research Ethics Board.

Descriptive statistics were completed on demographic variables. Demographic data included number of years in practice, nature of current practice (academic vs community), qualifications, fellowship or specialization training completed, marital status, number of children and age at the time of personal and professional milestones. Categorical data were presented with numeric values and percentages and compared using the Chi-square test. Fisher exact test was used if cell counts were less than five. Univariable logistic regression analysis was used to determine predictors of choosing the same career in urology. A p-value of $<0.05$ was used to indicate statistical significance for a two-tailed comparison. Statistical analyses were performed using SAS ${ }^{\circledR}$ version 9.4 (SAS Institute, Inc., Cary, NC, USA).

\section{Results}

Sixty women (75.0\%) responded to our survey (Table 2 ). While a response was not required for each item, we were missing at most one response for any given survey item. A large proportion of respondents had been in practice $<5$ years $(26 / 59,44.1 \%)$. Most women $(43 / 59,72.9 \%)$ completed fellowship or specialization training after residency, most commonly female urology $(16 / 59$, $27.1 \%)$, neurourology $(13 / 59,22.0 \%)$, reconstructive urology $(11 / 59,18.6 \%)$ and paediatrics $(10 / 59,16.9 \%)$. Overall, $88.4 \%$ reported that their current practice was reflective of their fellowship training. Thirty-four percent completed a graduate degree and approximately half of women were in academic practice (45.8\%). More than one third of women did not have an academic title (24/60, 40\%) while 36.7\% (22/60) were Assistant Professors, 10.5\% (6/60) were Associate Professors, and 8.3\% (5/60) were full Professors.

Women who completed the English version of the survey were more likely to have completed fellowship training $(91.4 \%$ vs $45.8 \%, p<0.001)$ compared to women who completed the French version. There were no differences between the two groups with respect to overall satisfaction, years in practice, post-graduate degree, or community versus academic practice (all $\mathrm{p}>0.05)$.

Women who practiced in an academic setting were more likely to have completed fellowship training $(92.6 \%$ vs $58.1 \%, \mathrm{p}=0.003)$ and have a graduate degree $(59.3 \%$ vs $12.9 \%$, $\mathrm{p}<0.001)$ compared to those practicing in the community. There were no differences between the groups with respect to overall satisfaction or years in practice (all $\mathrm{p}>0.05$ ). 


\section{Professional satisfaction}

More than half of women $(32 / 59,54.2 \%)$ were very satisfied with their career, with $96.6 \%(57 / 59)$ stating they were very satisfied or somewhat satisfied. Seeing more time-consuming patients and financial constraints within the health care system were the greatest source of dissatisfaction (Figure 2).

Women worked a median of 55 hours per week (IQR: 50-70) and had a median of eight hours of operative time per week (IQR: 8-12, not including cystoscopy time). Most women (36/60, $60.0 \%$ ) felt that they worked the same number of hours compared to their male colleagues while $11 / 60(18.3 \%)$ and $13 / 60(21.7 \%)$ felt they worked more and less, respectively. Sixty-nine percent (40/58) felt they had the same amount of operative time as their male colleagues, while 4/58 (6.9\%) felt they had more and 14/58 (24.1\%) felt they had less or significantly less. Sixty-three percent (38/60) reported that they received significant mentorship during their training, most commonly from a male urologist $(92.1 \%)$. Forty percent $(24 / 60)$ felt that it was difficult to find a mentor during their training. Multiple women reported the need for organized mentorship opportunities within the female urology community in Canada.

When asked how women practice differently than their male counterparts, the most common response was spending more time with patients (91.5\%), improved empathy/communication, and seeing more non-operative patients. Women commonly reported receiving many female urology referrals and fewer referrals within their area of specialization. In some instances, this is what motivated a change from community to academic practice. Overall, $75.0 \%(45 / 60)$ were satisfied with their current financial situation. However, women reported financial challenges with respect to maternity leave, unequal compensation due to fee schedule/salary, fewer referrals for surgical cases, more administrative work without associated compensation, and challenges with respect to salary negotiation.

\section{Gender discrimination in the workplace}

Overall, 39/60 (65.0\%) reported experiencing gender discrimination during their career, most commonly from a colleague or a patient (Figure 3). Many women who were interested in community practice during their training reported difficulties obtaining community exposure and at times not feeling welcome in a community environment. Women practicing in the community reported experiencing discrimination more often than women practicing in an academic setting ( $78.1 \%$ vs $51.9 \%, \mathrm{p}=0.034)$. Examples of perceived discrimination in the workplace included colleagues not allowing residents to attend the clinics of the female staff, referral pattern outside of known area of specialization, not being invited to participate in journal clubs, receiving a different level of tolerance from nursing staff compared to male colleagues, being bypassed on the operative list overnight, and discrete jokes about being female. One respondent reported that a patient refused to have an operation when they found out the covering staff was female. 


\section{Satisfaction with personal life}

Most respondents were married $(38 / 59,64.4 \%)$ or in a relationship (12/59, 20.3\%) (Table 2). Most women had at least one child $(43 / 59,72.9 \%)$. Most women had their first child after becoming a staff (61.4\%), 22.7\% had their first child during residency and 13.6\% during fellowship. Median age at the time of the birth of their first child was 33 years (IQR: 31-34) and 35 years (IQR: 34-38) at the time of the birth of their last child. Mean time for maternity leave was $17.1( \pm 8.3)$ weeks, and $30.2 \%(13 / 43)$ reported a pregnancy related complication that they believe was triggered by their work (pre-eclampsia, premature contractions/labour, and miscarriage).

Most women $(47 / 57,82.5 \%)$ were very satisfied with their family life. Half of women $(29 / 60,48.3 \%)$ reported taking on the primary role in running the home. Forty-three percent (19/44) reported taking on the primary role in childcare, and 38.6\% (17/44) reported equally shared childcare responsibilities with their partner. However, 74.6\% (44/59) felt their career compromised their personal life and family responsibilities, while $33.9 \%(20 / 59)$ felt that their personal life and family responsibilities have compromised their career. Challenges included less time for research, delayed childbearing, compromising on location of fellowship due to family responsibilities, compromises made for their spouse's career, and challenges with respect to missing family events for work. Many women reported setting their hours differently or booking fewer patients to spend more time with their families. More than half $(55.4 \%, 31 / 56)$ reported they would have had more children if they had a less demanding career.

\section{Would you choose urology again?}

Most women $(66.1 \%, 39 / 59)$ would choose urology again, $20.3 \%$ (12/59) would choose a nonsurgical subspecialty and $10.2 \%(6 / 59)$ would choose a career outside of medicine. Seventy percent of responders stated they would encourage their son/daughter to pursue a career in medicine. Univariable logistic regression analysis revealed that women who reported financial satisfaction were more likely to report that they would choose the same career in urology $(\mathrm{OR}=4.50,95 \% \mathrm{CI}: 1.31-15.52 ; \mathrm{p}=0.015)$. Language spoken, practice location, fellowship training, having children, experiencing discrimination, and effect of family life on career and vise-versa did not have a significant impact (Table 3 ).

\section{Discussion}

This was a nation-wide survey exploring professional and personal satisfaction among female urologists in English- and French-speaking Canada. With rising numbers of females in surgery, it is important to explore the personal and professional challenges these women face. Overall, our response rate was $75.0 \%$. Most women $(82.5 \%)$ were very satisfied with their personal and family life, and $96.6 \%$ stated they were very satisfied, or somewhat satisfied, with their career. Even though most respondents reported professional satisfaction, only two thirds of women would choose to pursue a career in urology again. 
The proportion of participants who reported professional satisfaction in this survey $(96.6 \%)$ is higher than a recent 2017 Canadian Medical Association workforce survey of 716 urologists $(89 \% \text { male, } 11 \% \text { female })^{6}$ in which $71 \%$ reported that they were satisfied or very satisfied with their career. In contrast, fewer respondents in this study would choose a career in urology again compared to a large American College of Surgery survey of over 8000 male and female surgeons of all specialities. They found that $74 \%$ of respondents would choose surgery again as a specialty ${ }^{7}$ compared to $66 \%$ in our survey.

With regards to personal milestones, most women had children $(72.9 \%)$ and most began their families once on staff. One third of women who had children reported a pregnancy related complication they felt was related to their work schedule or work environment. A cross-sectional study of 939 female physicians reported that women who worked more than 70 hours per week during the first trimester had a three-fold increased risk of experiencing a threatened abortion and 2.5 -fold increase in preterm birth after adjusting for specialty, maternal age, and income ${ }^{8}$. Two cohort studies in the US revealed similar findings $\mathrm{s}^{9,10}$. One study compared 92 female residents to the spouses of 144 male residents and found a 10-fold increased risk of premature labour among female residents ${ }^{9}$. A second study compared the outcomes of 67 pregnancies of practicing physicians to 201 pregnancies of non-physicians and found that physicians had a nearly two-fold increased risk of an adverse pregnancy outcome and a four-fold increased risk of preterm labour ${ }^{10}$. A survey of 243 female urologists in the US revealed a pregnancy-related complication rate of $25.3 \%$, most commonly premature labour/delivery ${ }^{11}$, which is similar to this study.

Training in surgery coincides with optimal timing for childbearing. In Ontario and Quebec, guidelines are in place for female residents with regards to duty hours restriction and maternity leave ${ }^{12,13}$. In our study, approximately $22.7 \%$ of women surveyed had children during residency. Based on the literature, it is difficult to estimate pregnancy rates within specific specialties, but the rate reported in this study seems to be comparatively lower than other specialties, such as paediatrics $(38 \%)^{14}$. With formal guidelines in place, there appears to be an improved culture of support for women taking maternity leave during residency. Nonetheless, in a recent survey of 347 female surgeons, $73 \%$ reported witnessing faculty members or other residents making negative comments about pregnant trainees or childbearing during training ${ }^{15}$. More than $80 \%$ felt that requesting accommodations for less demanding rotations during pregnancy would have been perceived negatively by their peers and supervising faculty ${ }^{15}$. More than one third of respondents strongly considered leaving their surgical residency program because of the difficulties in balancing pregnancy and motherhood with training ${ }^{15}$. Furthermore, women from a procedural specialty are more likely to report a negative impact on referrals by maternity leave ${ }^{16}$. Ensuring women are well supported with regards to duty hours during pregnancy and maternity leave requires more research and more support at both a resident and staff level.

In our study, gender discrimination was experienced by two thirds of responders and was more commonly reported by women practicing in the community. Gender discrimination and lack 
of mentorship have been cited as primary barriers to career advancement among female surgeons ${ }^{17}$. These factors contribute to ongoing discrepancies in terms of rank attainment, leadership roles, and salaries ${ }^{17}$. Despite having no difference in self assessed leadership ability, women are significantly less likely to be asked to serve in leadership roles ${ }^{18}$. In the field of urology specifically, proportionately fewer women achieve senior academic ranking ${ }^{19}$. In a meta-analysis evaluating job performance among professional women, females tended to outscore men on performance evaluations on average, yet had lower promotability ratings ${ }^{20}$. Facilitating mentorship, providing leadership training, and reducing discrimination moving forward will minimize this gender gap.

Discrepancies in financial compensation between males and females in urology have been reported $^{21}$. In 2016, it was shown that female gender was a significant predictor of lower compensation for physicians in the US after controlling for many factors and adjusted salaries were more than $\$ 80,000$ less than those of $m^{22}{ }^{22}$. While perhaps thought to be less of an issue in Canada where we operate in a single-payer fee-for-service environment, other sources of financial disparity were reported in our study. Differences in negotiating abilities, fewer operative referrals, increased administrative tasks without financial compensation, and maternity leave were sources of this perceived discrepancy. The discrepancy in operative referrals does not seem to be related to surgical ability. A recent cohort study of surgeons in Ontario revealed that post-operative mortality rates were improved for female compared to male surgeons, controlling for patient and surgeon confounders ${ }^{23}$. In a recent study in the US, female surgeons (even those who completed gender neutral subspecialty training) operated on a higher proportion of female patients compared to their male colleagues and performed significantly more female-specific procedures, such as slings ${ }^{24}$, which are known to be associated with lower renumeration. It should be acknowledged, however, that this discrepancy may be due to patient preference rather than surgical culture.

We found differences between women who practiced in Quebec compared to the rest of Canada. Female urologists who completed the French version of the survey were less likely to have completed fellowship training compared to those who completed the English version. However, there were no differences between the two groups with respect to overall satisfaction, years in practice, graduate degree completion, or practice location. Interestingly, we found that there were more actively practicing female urology staff in Quebec compared to the other provinces. The exact reason for this is not entirely clear, but perhaps may be related to increased urology exposure among medical students in Quebec, increased female mentorship, or perhaps simply a reflection of the fact that there are more female medical students ${ }^{25}$ and physicians ${ }^{26}$ in Quebec as a whole.

There are limitations to the current study. While many participants were actively registered with the CUA, the list provided was not comprehensive and additional informal strategies had to be used to increase our capture rate. Therefore, we have no way to know for certain that all female urologists were identified and there may be an element of sampling bias. While we made every 
effort to maintain anonymity, given that this is a small community there is potential for a Hawthorne effect whereby participants may have modified their responses if there was a concern they could be identifiable in the survey. Our small sample size is reflective of the small number of female urologists in Canada and is a limitation of this study. Nevertheless, our exploratory study achieved a high overall response rate and revealed important barriers and challenges within our speciality.

Urology is a speciality that allows for a diverse practice while providing a more flexible lifestyle when compared to many other surgical specialties. With more female medical students choosing to pursue a surgical speciality ${ }^{5}$, it is important to advocate for the women within the field of urology in Canada. To this end, we have established a formal circle of support, mentorship and promotion within the urology community in Canada. A formal meeting of female urologists in Canada now occurs on a yearly basis at the annual CUA meeting with the objective of forming of a formal society in the future.

\section{Conclusions}

It is important to advocate for the wellness of our current female urologists and to attract and maintain the most talented physicians in our field. To accomplish this, we need to address the challenges revealed in this survey by supporting women on maternity leave, incorporating maternity leave guidelines into contract negotiations, improving mentorship, prioritizing leadership initiatives, as well as acknowledging and combating gender discrimination in the workplace. 
Practice and career satisfaction patterns among female urologists

\section{References}

1. College of the American Medical Association. Number of Female Medical School Enrollees Reaches 10-Year High. 2016. Accessed 03/10/2018, 2018.

2. Baerlocher MO. Does sex affect residency application to surgery? Can J Surg. 2007;50(6):434-436.

3. CMA. Physician Data Centre: Canadian Physician Statistics. 2018. Accessed 3/10/2018, 2018.

4. Marley CS, Lerner LB, Panagopoulos G, et al. Personal, professional and financial satisfaction among American women urologists. Int Braz J Urol. 2011;37(2):187-192; discussion 192-184.

5. Anderson K, Tennankore K, Cox A. Trends in the training of female urology residents in Canada. Can Urol Assoc J. 2018;12(3):E105-E111.

6. CMA. Urology Profile. 2017. Accessed March 1, 2019.

7. Shanafelt TD, Balch CM, Bechamps GJ, et al. Burnout and career satisfaction among American surgeons. Ann Surg. 2009;250(3):463-471.

8. Takeuchi M, Rahman M, Ishiguro A, et al. Long working hours and pregnancy complications: women physicians survey in Japan. BMC Pregnancy Childbirth. 2014; $14: 245$.

9. Osborn LM, Harris DL, Reading JC, et al. Outcome of pregnancies experienced during residency. J Fam Pract. 1990;31(6):618-622.

10. Miller NH, Katz VL, Cefalo RC. Pregnancies among physicians. A historical cohort study. J Reprod Med. 1989;34(10):790-796.

11. Lerner LB, Stolzmann KL, Gulla VD. Birth trends and pregnancy complications among women urologists. J Am Coll Surg. 2009;208(2):293-297.

12. PARO. Your Contract. 2018. Accessed 01-10-2018, 2018.

13. FMRQ. Entente Intervenue. 2018. Accessed March 1, 2019.

14. Klevan JL, Weiss JC, Dabrow SM. Pregnancy during pediatric residency. Attitudes and complications. Am J Dis Child. 1990;144(7):767-769.

15. Rangel EL, Lyu H, Haider AH, et al. Factors Associated With Residency and Career Dissatisfaction in Childbearing Surgical Residents. JAMA Surg. 2018.

16. Scully RE, Davids JS, Melnitchouk N. Impact of Procedural Specialty on Maternity Leave and Career Satisfaction Among Female Physicians. Ann Surg. 2017;266(2):210-217.

17. Zhuge Y, Kaufman J, Simeone DM, et al. Is there still a glass ceiling for women in academic surgery? Ann Surg. 2011;253(4):637-643.

18. Wright AL, Schwindt LA, Bassford TL, et al. Gender differences in academic advancement: patterns, causes, and potential solutions in one US College of Medicine. Acad Med. 2003;78(5):500-508.

19. Mayer EN, Lenherr SM, Hanson HA, et al. Gender Differences in Publication Productivity Among Academic Urologists in the United States. Urology. 2017;103:39-46.

20. Roth P, Purvis K, Bobko P. A Meta-Analysis of Gender Group Differences for Measures of Job Performance in Field Studies. Vol 38 (2). Journal of Management2012:719-739. 
21. Halpern JA, Lee UJ, Wolff EM, et al. Women in Urology Residency, 1978-2013: A Critical Look at Gender Representation in Our Specialty. Urology. 2016;92:20-25.

22. Spencer ES, Deal AM, Pruthi NR, et al. Gender Differences in Compensation, Job Satisfaction and Other Practice Patterns in Urology. J Urol. 2016;195(2):450-455.

23. Wallis CJ, Ravi B, Coburn N, et al. Comparison of postoperative outcomes among patients treated by male and female surgeons: a population based matched cohort study. BMJ. 2017;359:j4366.

24. Oberlin DT, Vo AX, Bachrach L, et al. The Gender Divide: The Impact of Surgeon Gender on Surgical Practice Patterns in Urology. J Urol. 2016;196(5):1522-1526.

25. AFMC. The Association of Faculties of Medicine of Canada: Q1g What are the demographics of students admitted to Canadian medical schools. 2017.

26. CIHI. Physicians in Canada, 2016: Statistics report. 2017. 


\section{Figures and Tables}

Fig. 1. Distribution of actively practicing female staff urologists across Canada, $n=80$.

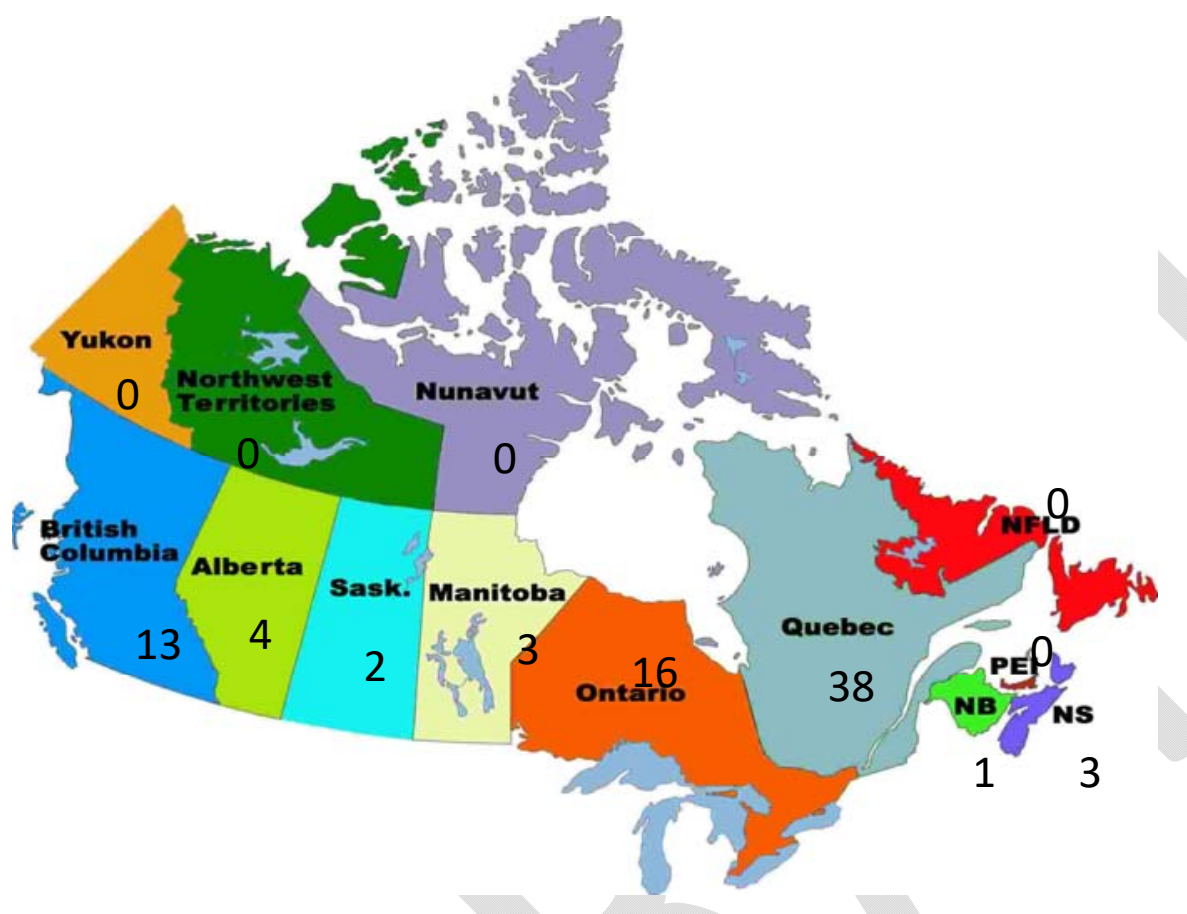

Fig. 2. Greatest causes of professional dissatisfaction (y-axis) among female staff urologists in Canada (total number of respondents $=60$; number of respondents who completed the English survey $=35$; number of respondents who completed the French survey $=25$ )

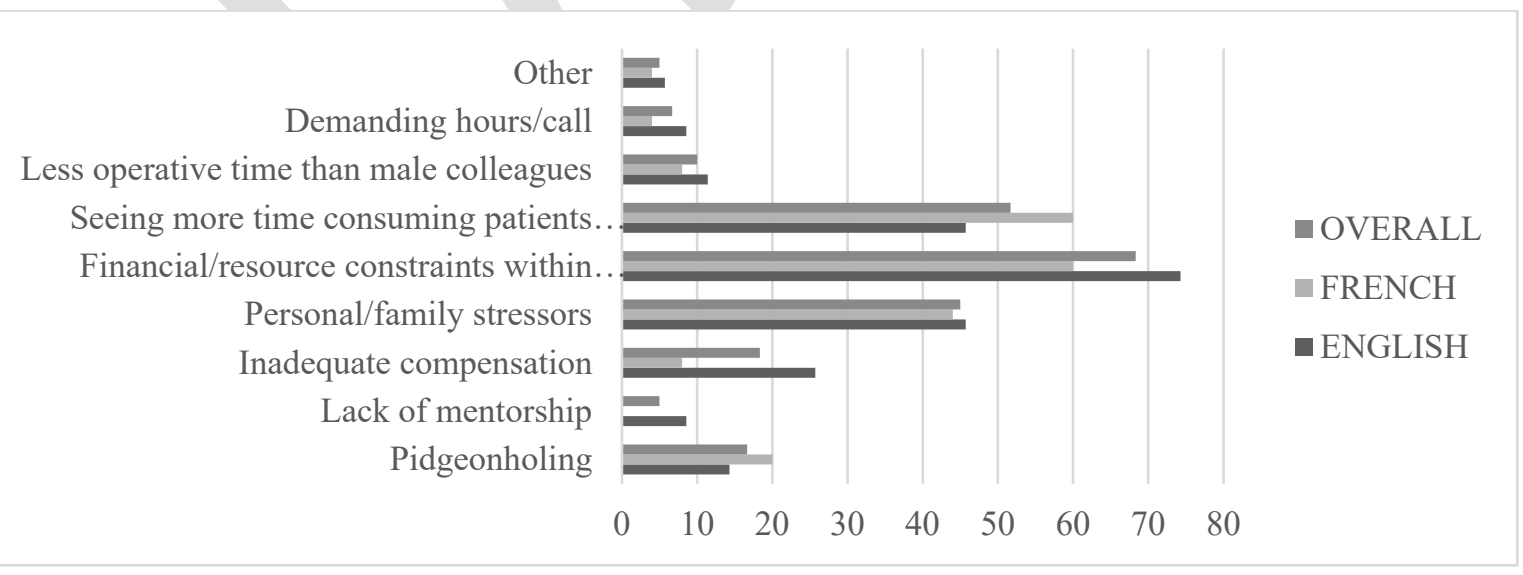


Fig. 3. Source of perceived gender discrimination in the workplace (y-axis) among female staff urologists in Canada (total number of respondents $=60$; number of respondents who completed the English survey=35; number of respondents who completed the French survey=25)

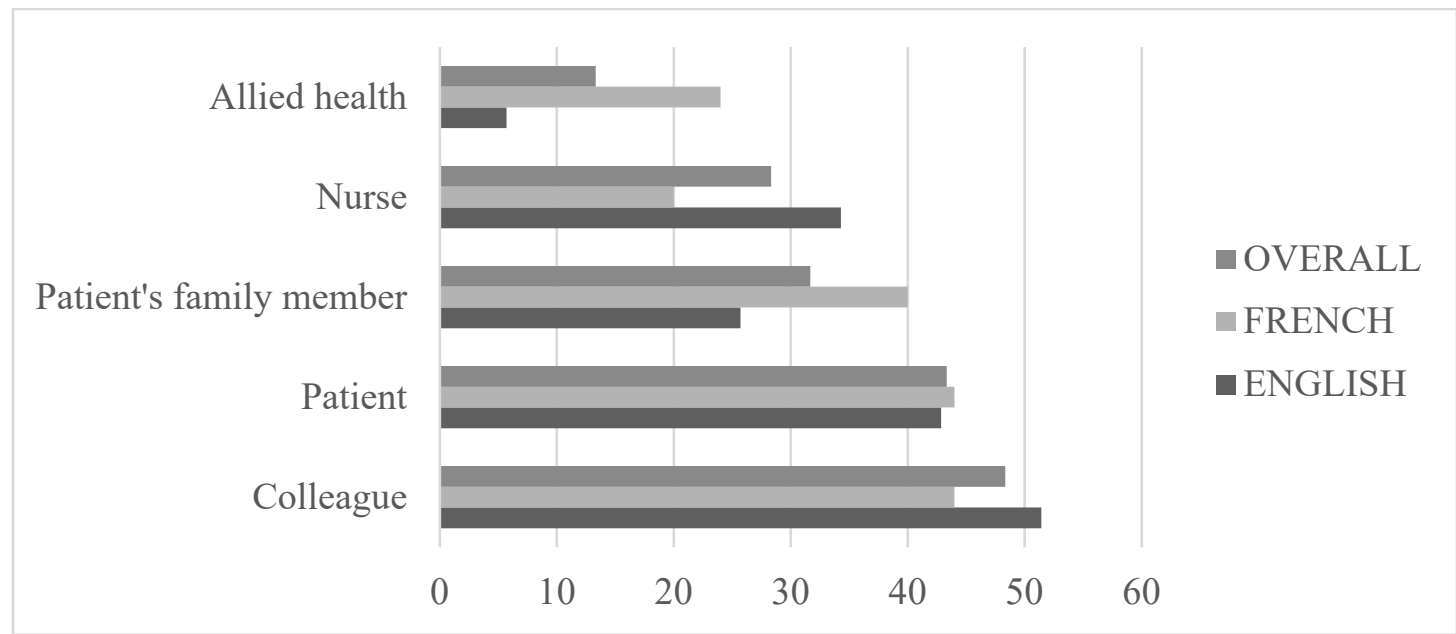

\section{Table 1. Summary of survey items \\ Demographic Information}

Years in practice

Fellowship completed

Graduate degree completed and timing

Age at completion of residency and fellowship

Nature of current practice

Academic title

Martial status

Children and timing of children

\section{Professional}

Satisfaction with career

Hours worked per week

Hours in the operating room per week (excluding cystoscopy)

Number of days at work per week

Operative time compared to male colleagues

Mentorship during training

Differences in practice style compared to male colleagues

Time spent with patients compared to male colleagues

Pay compared to male colleagues

Greatest source of dissatisfaction in your practice 


\begin{tabular}{|l|}
\hline Gender discrimination in the workplace \\
\hline Personal \\
\hline Time for maternity leave \\
\hline Pregnancy complications related to your work schedule/environment \\
\hline Role in running the home \\
\hline Role in childcare \\
\hline Satisfaction from family life \\
\hline Family life compromised career \\
\hline Career compromised family life \\
\hline More children if job was less demanding \\
\hline Satisfaction with financial situation \\
\hline Overall \\
\hline Would you choose urology again \\
\hline Would you encourage your children to pursue a career in medicine \\
\hline
\end{tabular}




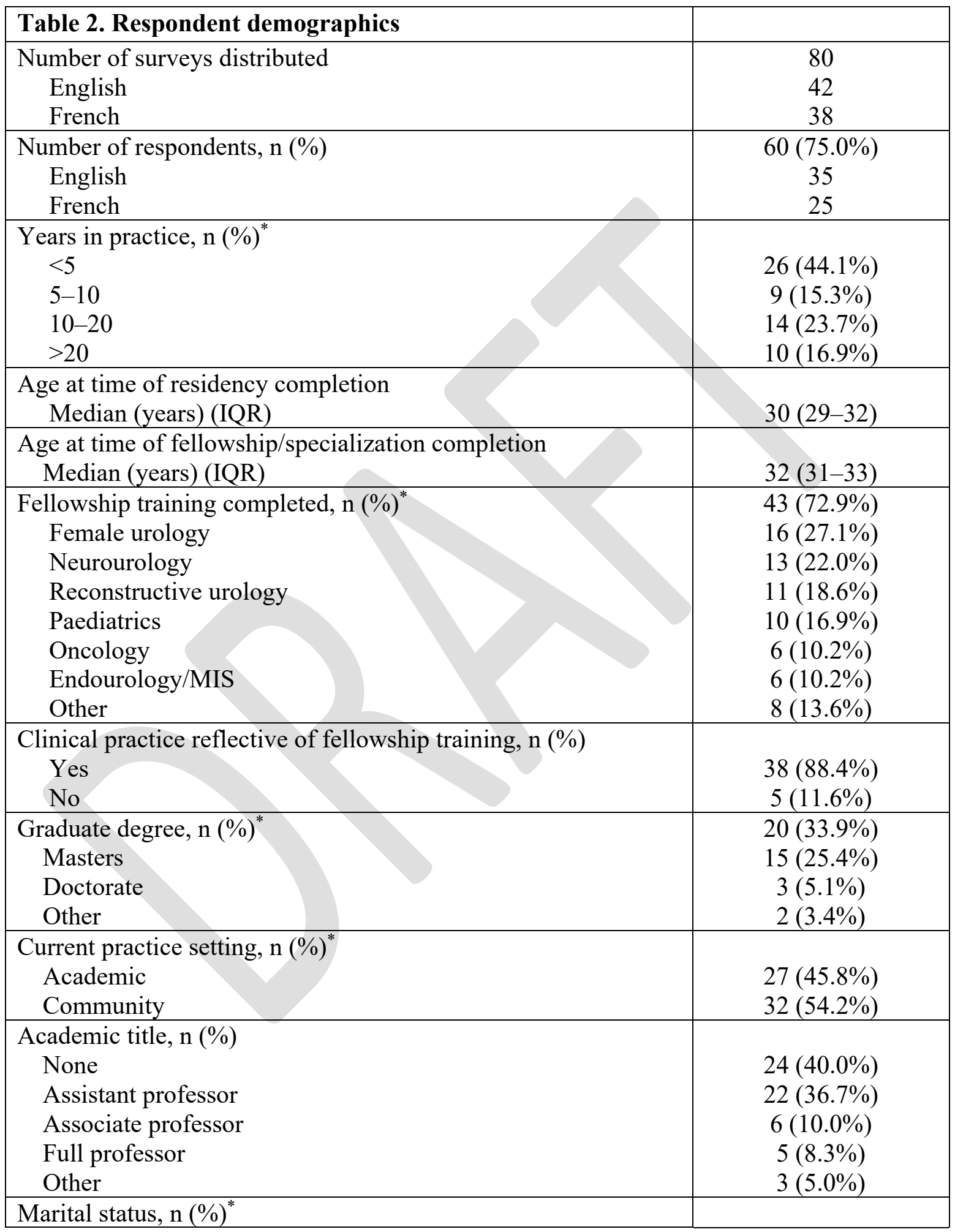




\begin{tabular}{|l|c|}
\hline Married/remarried & $38(64.4 \%)$ \\
Single/divorced/separated & $9(15.3 \%)$ \\
In a relationship & $12(20.3 \%)$ \\
\hline Children, n (\%) & \\
Yes & $43(72.9 \%)$ \\
No & $16(27.1 \%)$ \\
\hline Age at time of first child & $33(31-34)$ \\
Median (years) (IQR) & \\
\hline Age at time of last child & $35(34-38)$ \\
Median (years) (IQR) & \\
\hline
\end{tabular}

*Missing one response, $\mathrm{N}=59$. IQR: interquartile range; MIS: minimally invasive surgery.

\begin{tabular}{|l|l|c|c|}
\hline \multicolumn{4}{|l|}{$\begin{array}{l}\text { Table 3. Univariable logistic regression analysis of predictors of whether a } \\
\text { participant would choose urology as a speciality again }\end{array}$} \\
\hline Variable & OR & $\mathbf{9 5 \%}$ CI & p \\
\hline $\begin{array}{l}\text { Language } \\
\text { (reference=English) }\end{array}$ & 1.99 & $0.64-6.28$ & 0.227 \\
\hline $\begin{array}{l}\text { Location of practice } \\
\text { (reference=Community) }\end{array}$ & 0.95 & $0.32-2.86$ & 0.931 \\
\hline $\begin{array}{l}\text { Fellowship } \\
\text { (reference: No) }\end{array}$ & 0.61 & $0.17-2.25$ & 0.453 \\
\hline Discrimination (reference: No) & 1.50 & $0.49-4.61$ & 0.481 \\
\hline $\begin{array}{l}\text { Children } \\
\text { (reference: No) }\end{array}$ & 1.20 & $0.36-3.98$ & 0.766 \\
\hline $\begin{array}{l}\text { Career compromised family life } \\
\text { (reference: No) }\end{array}$ & 0.38 & $0.09-1.56$ & 0.157 \\
\hline $\begin{array}{l}\text { Family life compromised career } \\
\text { (reference: No) }\end{array}$ & 0.69 & $0.23--2.14$ & 0.523 \\
\hline $\begin{array}{l}\text { Financial satisfaction } \\
\text { (reference: No) }\end{array}$ & 4.50 & $1.31-15.52$ & 0.015 \\
\hline
\end{tabular}

CI: confidence interval; OR: odds ratio. 